Check for updates

Cite this: J. Mater. Chem. A, 2021, 9 , 16222

Received 3rd May 2021

Accepted 25th June 2021

DOI: $10.1039 / \mathrm{d} 1 \mathrm{ta0} 3710 \mathrm{~b}$

rsc.li/materials-a

\section{Organic materials as photocatalysts for water splitting}

\begin{abstract}
Yang Bai, (D) ${ }^{a}$ Kedar Hippalgaonkar (iD ${ }^{\text {ab }}$ and Reiner Sebastian Sprick (D) *c
Solar water splitting offers a potential avenue for the production of clean and storable energy in the form of hydrogen. Semiconductors can be used as photocatalysts that enable the simultaneous production of hydrogen and oxygen from water via water splitting and in recent years inorganic semiconductor photocatalysts have been significantly improved in terms of their performance with organic semiconductors emerging as a potential alternative, though mostly studied for sacrificial half-reactions. Herein, we present recent developments in using organic semiconductors as photocatalysts highlighting their potential due to their synthetic tunability. We will particularly focus on their application in overall water splitting without using sacrificial reagents and suggest future directions in using these materials in large scale applications before concluding with suggestions for a wider community to focus research efforts on particular challenges in the field and opportunities that organic materials offer.
\end{abstract}

\section{Introduction}

The use of fossil fuels in energy generation and propulsion has resulted in the emission of large amounts of carbon dioxide. ${ }^{1}$ This has resulted in an increase of Earth's surface and air temperature contributing to climate change. ${ }^{2}$ As the effects of climate change are becoming more and more apparent, our society has to make the transition to renewable energy sources that do not emit greenhouse gases. The conversion of wind, solar and other renewable energy sources is expected to deliver most of the useful electric energy in the future. ${ }^{3}$ However, a major problem with electric energy is its storage, which might be a particular problem for its mass use in propulsion. ${ }^{4}$ Another significant risk is the intermittency of wind and solar in energy generation; thus we will still require storable fuels to compensate for fluctuations in their use and availability. Hydrogen has been identified as a possible storable fuel that could overcome these limitations. Electricity can be used for water electrolysis generating hydrogen and oxygen gases..$^{5}$ As an alternative to this, photoelectrochemical and photochemical processes directly split water using sunlight. ${ }^{6,7}$ In particular photochemical approaches are highly interesting as they allow for technologically simple solutions only requiring water and a photocatalyst to facilitate water splitting. ${ }^{8}$ Here we summarise recent developments in the area of organic photocatalysts,

${ }^{a}$ Institute of Materials Research and Engineering, Agency for Science, Technology and Research, \#08-03, 2 Fusionopolis Way, Innovis, Singapore 138634, Singapore

${ }^{b}$ School of Materials Science and Engineering, Nanyang Technological University, 639798, Singapore

'Department of Pure and Applied Chemistry, University of Strathclyde, Thomas Graham Building, 295 Cathedral Street, Glasgow G1 1XL, UK. E-mail: sebastian. sprick@strath.ac.uk present the state-of-the-art in terms of their overall water splitting performance and highlight their potential for future largescale applications.

\section{Mechanism of photocatalytic overall water splitting}

For the application of photocatalytic water splitting on a large scale, solar-to-hydrogen efficiencies of approximately $10 \%$ have been suggested to be required. This means that $10 \%$ of the solar incident light energy that reaches the catalyst surface is used to convert water into hydrogen gas. ${ }^{9}$ Even the current state-of-theart systems are not close to achieving this as materials have to fulfill a range of requirements.

For photocatalytic water splitting to occur a material is needed, which (i) absorbs visible light; (ii) has suitable band positions straddling the water oxidation and reduction potential; (iii) is able to generate electron-hole pairs upon irradiation and suppresses recombination sufficiently; (iv) is able to separate electron-hole pairs and transport charge carriers to active
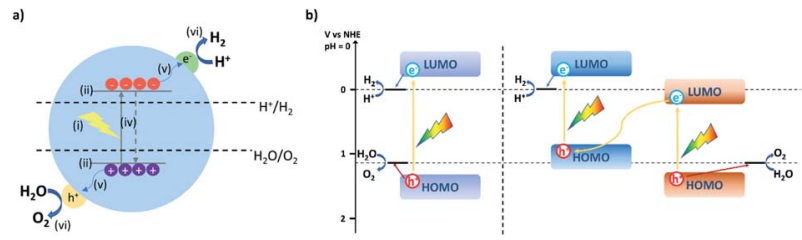

Fig. 1 (a) Diagram showing the reactions during water splitting on a semiconductor photocatalyst; (b) working principle of single component photocatalysts (left) and photocatalyst $Z$-schemes (right) for overall water splitting. 
sites; (v) is able to transfer charge to water and release the produced hydrogen and oxygen (Fig. 1a). ${ }^{\mathbf{1 0}}$

Semiconductors that fulfill all these requirements are able to drive overall water splitting in principle. However, in most cases metal co-catalysts are required to facilitate hole and electron transfer reactions and many materials struggle to straddle both the water oxidation and proton reduction potential with a sufficient overpotential to drive both processes simultaneously.

Therefore, often multicomponent systems are used with one component driving proton reduction with a second component performing water oxidation (Fig. 1b). This allows matching either component to the required overpotential for the halfreactions but requires twice as many photons as both components have to be excited. These can be systems that rely on direct contact or through a mediator, such as a water-soluble redox active component in a so-called $Z$-scheme, ${ }^{\mathbf{1 1}}$ or a solidstate electron mediator, such as carbon nanotubes ${ }^{\mathbf{1 2}}$ or reduced graphene oxide. ${ }^{13}$

Inorganic semiconductors have been extremely well studied for photocatalytic water splitting. Initially focusing on proton reduction and water oxidation half-reactions whereby the other half-reaction is suppressed by a sacrificial regent, systems with good activity for overall water splitting have been developed. Systems such as $\mathrm{SrTiO}_{3}: \mathrm{La}, \mathrm{Rh}$ and $\mathrm{BiVO}_{4}:$ Mo embedded into a gold layer have achieved solar-to-hydrogen efficiencies (STHs) of $1.1 \%$ and an external quantum efficiency (EQE) at $420 \mathrm{~nm}$ of over 30\%. ${ }^{14}$ Aluminium-doped strontium titanate loaded with $\mathrm{Rh} / \mathrm{Cr}_{2} \mathrm{O}_{3}$ and $\mathrm{CoOOH}$ cocatalysts achieved an EQE 95.9\% at $360 \mathrm{~nm}$, though the STH was low $(0.65 \%)$ as the material is only able to absorb UV light, which only makes up less than $5 \%$ of the Sun's irradiation that reaches the Earth's surface. ${ }^{15}$ Stability has also been demonstrated with Al-doped $\mathrm{SrTiO}_{3}$ loaded with $\mathrm{RhCrO}_{x}$ following the photodeposition of $\mathrm{CoOOH}$ and $\mathrm{TiO}_{2}{ }^{16}$ The material maintains $80 \%$ of its initial activity and a STH greater than or equal to $0.3 \%$ over 1300 hours under constant simulated sunlight illumination and at ambient pressure.

\section{Development of polymeric photocatalysts for hydrogen evolution}

By contrast organic semiconductors have been far less studied for water splitting compared to inorganic semiconductors even though they are potentially very interesting candidates given their tunability using a wide range of synthetic approaches: palladium-catalysed cross coupling reactions, such as SuzukiMiyaura, ${ }^{17,18}$ Stille $^{19}$ and Sonogashira reactions, ${ }^{20}$ have been widely used to make photocatalysts, but all require functionalised monomers bearing two different functional groups (e.g. boronic acids and bromine compounds in the case of SuzukiMiyaura coupling). Kumada coupling reactions also require two different functional groups for the coupling reaction to take place; however, the required Grignard functional group can be generated in situ from multi-halide bearing compounds. ${ }^{17}$ Yamamoto coupling reactions require stoichiometric amounts of nickel(0), but couple compounds bearing multiple halides without further functionalisation. ${ }^{21}$
A wide range of metal-free reactions have also been used to make organic photocatalysts. Methods such as oxidative coupling reactions, ${ }^{20}$ imine condensation, ${ }^{22}$ Knoevenagel condensation $^{23}$ and cyclotrimerization reactions ${ }^{24,25}$ yield polymeric products. Using these methods, materials can be obtained that are free from palladium or nickel impurities, which appear to act as co-catalysts (vida infra).

Synthetic tools can be used in the coupling of a very large number of potential building blocks allowing the easy tuning of the properties of the materials. Furthermore, the materials are made from light and abundant elements thus potentially allowing these materials to be made cheaply on a large scale.

The first widely explored example of a photocatalytic polymer is carbon nitride, first reported in $2009 .{ }^{26}$ Carbon nitride $\left(\mathrm{C}_{3} \mathrm{~N}_{4}\right)$ is composed of carbon, nitrogen, and a small amount of hydrogen. The idealised $\mathrm{C}_{3} \mathrm{~N}_{4}$ structure consists of linked $s$ triazine or heptazine (tri-s-triazine) units although the exact structure is unknown and are likely to contain mixtures of these units and structural defects. The report showed that indeed an organic semiconductor could perform both half-reactions, though not simultaneously and additionally requiring sacrificial reagents to drive both processes. Following this report, a large number of follow-up studies reported many variants of carbon nitrides for sacrificial half-reactions..$^{26-30}$ Materials such as polymeric carbon nitride can archive high apparent quantum yields (AQYs, defined as percentage of electrons used for the generation of hydrogen per incident photons). For example, carbon nitride has been reported with improved AQYs after post-synthesis calcination the presence of eutectic salts. This resulted in an AQY as high as $60 \%$ at $420 \mathrm{~nm}$ from aqueous 3 $\mathrm{wt} \% \mathrm{NaCl}$ solution, in the presence of TEOA as the sacrificial donor. $^{31}$

Covalent triazine-based frameworks (CTFs) are related to carbon nitrides regarding their high nitrogen content but are (unlike carbon nitrides) accessible using low temperatures using acid-catalysed trimerisation reactions or Suzuki-Miyaura type polycondensation reactions. ${ }^{32}$ CTFs are able to facilitate photocatalytic hydrogen evolution from water, with platinum co-catalysts and in the presence of sacrificial agents. A large number of structurally diverse CTFs have been reported to be active $^{24,33}$ with quantum yields as high as $15.9 \%$ at $420 \mathrm{~nm}$ under sacrificial conditions.

Conjugated microporous polymers (CMPs) were reported as a new class of porous materials by the Cooper group in $2007 .{ }^{34}$ The same group reported a series of conjugated microporous polymers (CMPs) in 2015, where the optical gap was tuned by changing the proportions of phenyl and pyrene building blocks. Specific monomer compositions give polymers that are robust and effective photocatalysts for the evolution of hydrogen from water in the presence of TEA as a sacrificial electron donor, without a post-loading metal cocatalyst. ${ }^{35}$ The photocatalytic activity has been improved by using different building blocks in CMPs, such as benzothiadiazole, ${ }^{36}$ 3,8-dibromophenanthroline ${ }^{37}$ dibenzo $[b, d]$ thiophene sulfone, ${ }^{38}$ and 2,1,3-benzothiadiazole (Fig. 2). ${ }^{39}$

Covalent organic frameworks (COFs) are porous materials composed of organic molecules linked by covalent bonds and 


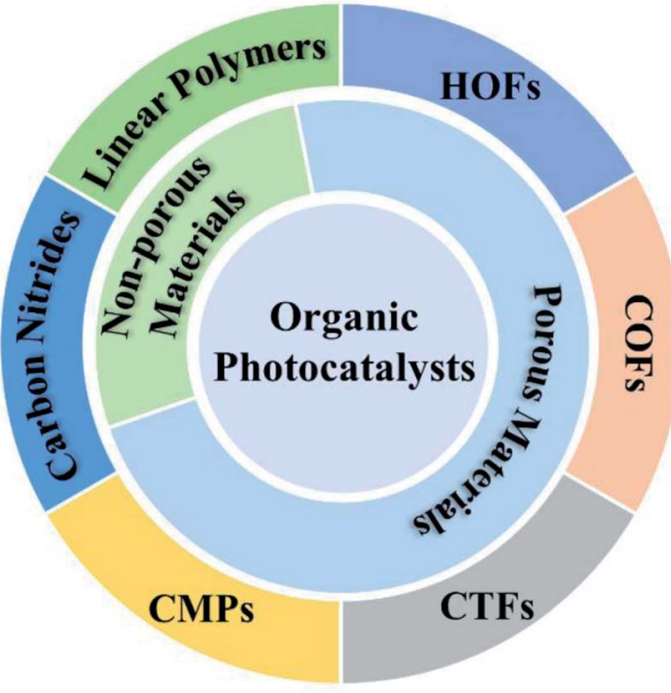

Fig. 2 Classes of organic materials that have been studied as photocatalysts for water splitting. CMPs: conjugated microporous polymers; CTFs: covalent triazine-based frameworks, COFs: covalent organic frameworks; HOFs: hydrogen-bonded organic frameworks.

they show a higher degree of crystallinity compared to carbon nitrides and CTFs. The first photocatalytically active COF, a hydrazone-based material (TFPT-COF), was reported by the Lotsch group in 2014 to perform photocatalytic hydrogen evolution under visible light irradiation in the presence of triethanolamine (TEOA) as the sacrificial agent and loaded with platinum acting as the co-catalyst. ${ }^{40}$ The same research group subsequently reported a series of $2 \mathrm{D}$ azine COFs with an impressive photocatalytic HER of up to $1.7 \mathrm{mmol} \mathrm{g}^{-1} \mathrm{~h}^{-1}$. $^{41} \mathrm{In}$ 2018, a crystalline COF, FS-COF, based on a benzobis(benzothiophene sulfone) moiety was presented by the Cooper group, which shows a much higher activity for photochemical hydrogen evolution than other previously reported COFs. ${ }^{22}$ The pores in FS-COF allow this framework to be dyesensitised, leading to a further $61 \%$ enhancement in the hydrogen evolution rate up to $16.3 \mathrm{mmol} \mathrm{g}^{-1} \mathrm{~h}^{-1}$. This is still the highest photocatalytic activity for hydrogen evolution from water for COFs so far. Ghosh and coauthors have reported a series of COFs recently, and showed that the light absorption and charge carrier generation and transport of the series of COFs have a greater influence on the photocatalytic $\mathrm{H}_{2}$ production compared to other material factors. ${ }^{42}$

Unbranched polymers, namely poly( $p$-phenylene), have been reported as early as 1985 to be active for sacrificial hydrogen production from water by the Yanagida group. ${ }^{43}$ The photocatalytic activity was low, due to a wide bandgap of $2.9 \mathrm{eV}$.

The incorporation of heteroatoms improved important parameters such as narrowing the band gap allowing for more light to be absorbed and increasing wettability. As such pyridyl polymers, ${ }^{21}$ thiophene co-polymers ${ }^{19}$ and dibenzo $[b, d]$ thiophene sulfone co-phenyl polymers ${ }^{17}$ were reported subsequently with much higher activities with an EQE of $20.7 \%$ at $420 \mathrm{~nm}$ for dibenzo $[b, d]$ thiophene sulfone co-dibenzo $[b, d]$ thiophene polymer.
Heterojunctions of donor polymers with organic acceptors have also been developed to facilitate intermolecular charge transfer and transport to boost the photocatalytic performance. McCulloch's group has reported a core-shell structure for an intermixed donor/acceptor blend with an extremely high photocatalytic activity for hydrogen evolution of $60 \mathrm{mmol} \mathrm{h}^{-1} \mathrm{~g}^{-1} \cdot{ }^{44}$ Later on, a higher hydrogen evolution rate of $105 \mathrm{mmol} \mathrm{h}^{-1} \mathrm{~g}^{-1}$ under visible light was reported using other conjugated polymer donors and fullerene molecular acceptors in nanohybrid systems. ${ }^{45}$ Systems consisting of two $^{46}$ or three ${ }^{47}$ different conjugated polymer photocatalysts have also been shown to be efficient for sacrificial hydrogen production by providing an energy offset for charge transfer.

Hydrogen-bonded organic frameworks have also been shown to be active recently ${ }^{48}$ The highly ordered $\alpha$-phase of tetra(4carboxyphenyl)pyrene showed a much higher photocatalytic activity for hydrogen evolution from water in the presence of ascorbic acid as a sacrificial electron donor, compared with its amorphous analogue under the same conditions with an AQY of $4.1 \%$ at $420 \mathrm{~nm}$ showing that a backbone with extended conjugation is not a prerequisite for high activity.

A very important and still debated question is whether or not metal catalysts are required to drive sacrificial hydrogen production. For the dibenzo $[b, d]$ thiophene sulfone homopolymer P10, it has clearly been demonstrated that the photocatalytic performance depends on its palladium content with a performance increase from $2825 \mu \mathrm{mol} \mathrm{h}^{-1} \mathrm{~g}^{-1}$ to $5332 \mu \mathrm{mol} \mathrm{h}{ }^{-1} \mathrm{~g}^{-1}$ by increasing the palladium content from $2000 \mathrm{ppm}$ to $7000 \mathrm{ppm}^{56}$ When poly(9,9-dioctylfluorene-alt-benzothiadiazole) F8BT was purified using preparative gel permeation chromatography and additional palladium scavengers reducing the residual amount of palladium originating from its synthesis to sub-ppm levels, it was found to make the material inactive. ${ }^{57}$ This is very strongly indicative of the palladium acting as a catalyst facilitating the proton reduction reaction, with other reports coming to the same conclusion for other materials.$^{58}$ Materials reported in earlier studies in the area contained large amounts of palladium, which most likely will also act as the catalyst for proton reduction. ${ }^{17,59}$ However, studies have also reported activity for materials in the absence of metal catalysts. These materials either contain no metal from the synthesis ${ }^{60-62}$ or the metal contamination levels are low after synthesis and purification. ${ }^{63}$ Molecular mechanisms are suggested to be responsible for hydrogen production instead of mechanisms that involve metals that are performing proton reduction. Clearly much more detailed studies are needed that show the existence of intermediates experimentally to rule out that low levels of metal contamination are responsible for the materials' activity.

\section{Water oxidation with conjugated materials}

Water oxidation remains a significant challenge for organic materials due to the required low lying HOMO levels to facilitate the process and the kinetic barrier that has to be overcome. ${ }^{64}$ While oxygen itself has little value, it is an important step forward towards developing photocatalysts for overall water 
splitting. So far only a few examples have been presented that facilitate water oxidation using organic photocatalysts, most requiring a metal co-catalyst to overcome the kinetic barrier of the process and the short lifetime of the holes.

Most reports so far have used either $\mathrm{CoO}_{x}$ or $\mathrm{RuO}_{x}$ co-catalysts, ${ }^{65-67}$ which are deposited onto the photocatalyst using impregnation, photodeposition or calcination methods. Alternatively, the co-catalyst can be preformed and then coated onto the photocatalyst by ultrasonication. ${ }^{68} \mathrm{Co}(\mathrm{OH})_{2}$ can also be formed in the presence of a photocatalyst by alkaline treatment of water-soluble cobalt(II) salts. ${ }^{69}$

In particular, carbon nitrides have been studied for photocatalytic water oxidation with the first report by Xinchen Wang in 2009 showing low, ${ }^{26}$ but detectable, levels of oxygen evolution using silver nitride as the electron scavenger and in the presence of $\mathrm{RuO}_{2}$ acting as the catalyst. ${ }^{70}$ The relatively wide bandgap with low-lying HOMO levels enables oxygen production and since this initial report the activity of carbon nitrides has been significantly improved by various approaches. ${ }^{28,71}$

CTFs are materials that are similar to carbon nitrides with respect to their high nitrogen content and low-lying HOMO levels. The fact that meta-links are present in this material class due to the triazine core also reduces the HOMO levels ${ }^{72}$ together with the electronegativity of the nitrogen atoms. ${ }^{73}$ CTFs have been shown to be active for sacrificial oxygen production after loading with $\mathrm{RuO}_{2}$ (ref. 74 and 75) with systems reaching rates of up to $140 \mu \mathrm{mol} \mathrm{h}{ }^{-1} \mathrm{~g}^{-1}$. Aza-CMP nanosheets, the condensation product of benzenetetramine and hexaketocyclohexane, have been reported to show activity for oxygen evolution from water in the presence of $\mathrm{FeCl}_{3}$ without additional metal catalysts. ${ }^{69}$ Similar to other materials reported for oxygen evolution, it is nitrogen-rich and has meta-linkages resulting in the required deep HOMO levels. The authors suggest a molecular mechanism with hole accumulation occurring on one carbon atom based on computational predictions, but without further experimental evidence. Similar to other reported photocatalysts, adding cobalt as a co-catalyst has been reported to improve the performance for photocatalytic $\mathrm{O}_{2}$ evolution up to $14.3 \mu \mathrm{mol} \mathrm{h}{ }^{-1}$ under visible light. Similarly, a crystalline perylene imide polymer has been reported to facilitate sacrificial oxygen evolution without additional co-catalysts under visible light with an oxygen evolution rate of $3223.9 \mu \mathrm{mol} \mathrm{g}{ }^{-1} \mathrm{~h}^{-1} .^{76}$ No possible mechanism for the hole transfer was suggested and it is unclear how water oxidation occurs using this material. Nanosized poly(diphenylbutadiyne) has been reported to show photocatalytic activity for water oxidation in the absence of any cocatalyst or sacrificial agents suggesting the oxygen reduction reaction to be responsible for balancing the charges generated by the system. ${ }^{77}$

A bipyridine-based covalent organic framework coordinating with $\mathrm{Co}^{2+}$ has been reported for photocatalytic water oxidation with an oxygen evolution rate of $152 \mu \mathrm{mol} \mathrm{g} \mathrm{g}^{-1} \mathrm{~h}^{-1}$ under sacrificial conditions. ${ }^{78}$ The co-catalyst was found to be crucial, and no activity was found in the absence of co-catalysts.

Linear conjugated organic polymer photocatalysts were also found to be active for sacrificial water oxidation. ${ }^{65}$ Materials that lack overpotential for water oxidation, such as $\operatorname{poly}(p$ - phenylene) and poly(thiophene), showed no activity, while a range of nitrogen containing materials were found to have oxygen evolution rates between 0.2 and $4.9 \mu \mathrm{mol} \mathrm{h} \mathrm{h}^{-1}$ under broadband irradiation. The most active material in this study was the homopolymer of dibenzo $[b, d]$ thiophene sulfone with a rate of $16.6 \mu \mathrm{mol} \mathrm{h}^{-1}$ under broadband irradiation and a rate of $5.2 \mu \mathrm{mol} \mathrm{h}{ }^{-1}$ under visible light. The co-catalysts were loaded onto the materials by photodeposition and found to be crucial with $\mathrm{CoO}_{x}$ giving the highest performance. Transient absorption spectroscopy showed that oxidative quenching occurs at very early timescales ( $0.5 \mathrm{ps}$ ) suggesting, together with the changes in the ground state UV/vis absorption spectra, a degree of pre-association between the electron scavenger (silver nitride) and the polymer.

Fully planarised nitrogen-containing conjugated ladder polymers have recently been reported to produce oxygen from water under visible light irradiation with an OER of 7.16 and $1.83 \mu \mathrm{mol} \mathrm{h}{ }^{-1}$, using $\mathrm{AgNO}_{3}$ as the electron scavenger and $\mathrm{La}_{2} \mathrm{O}_{3}$ as the $\mathrm{pH}$ buffering agent. ${ }^{79}$

Overall, only a few reports with relatively low rates when compared to hydrogen production catalysts have been reported; however, the development of these systems is a critical step forward to obtain fully organic photocatalysts for overall water splitting.

Potential stability challenges arise for conjugated materials from the production of oxygen: it is well known that many organic materials are not stable towards reactive oxygen species. ${ }^{\mathbf{8 6}}$ This can result in structural changes, such as ketodefect formation in polyfluorenes, ${ }^{87}$ addition reactions that break the conjugation in benzodithiophene units in the polymer chain $^{88}$ or even the breakdown of the polymer chain as demonstrated for poly[2-methoxy-5-(2'-ethylhexyloxy)-p-phenylene vinylene]. ${ }^{89}$

The photo-oxidation of organic materials can be suppressed by the addition of reactive oxygen species scavengers such as nickel(II) dibutyldithiocarbamate. ${ }^{90}$ The addition of this nickel complex has been shown to enhance the stability of organic photocatalysts for sacrificial hydrogen production.91 Alternatively, the addition of electron acceptors (such as $\mathrm{C}_{60}$ and derivatives) can be a potential strategy to enhance the stability of conjugated materials. ${ }^{92,93}$ This allows for faster electron transfer allowing the materials to be de-excited from highly reactive excited states. ${ }^{94}$ The use of blends of acceptor molecules and polymer photocatalysts has already been demonstrated for sacrificial hydrogen production, ${ }^{\mathbf{4 4 5}}$ and further studies are needed to explore whether this also results in higher overall stability towards oxidation.

\section{Organic materials for overall water splitting}

In contrast to the photocatalytic hydrogen production halfreaction that has been extensively studied, there are only a few examples of overall water splitting with organic materials. $Z$ Schemes allow the coupling of an organic photocatalyst that performs hydrogen production with an inorganic 
Table 1 Summary of materials for $Z$-schematic overall water splitting

Photocatalyst

Gas evolution

rates

\begin{tabular}{|c|c|c|c|c|c|c|c|c|c|c|c|}
\hline & & & & & & & & & & & \\
\hline $\mathrm{C}_{3} \mathrm{~N}_{4}(3 \mathrm{wt} \% \mathrm{Pt})$ & $\mathrm{BiVO}_{4}$ & $1: 1$ & NA & $\mathrm{FeCl}_{2}$ & $2.4-3$ & NA & $\begin{array}{l}15 \\
\left(g^{-1}\right)\end{array}$ & $8\left(g^{-1}\right)$ & 300 & $\begin{array}{l}\text { None (full } \\
\text { arc) }\end{array}$ & 49 \\
\hline $\mathrm{C}_{3} \mathrm{~N}_{4}(3 \mathrm{wt} \% \mathrm{Pt})$ & $\mathrm{WO}_{3}(0.5 \mathrm{wt} \% \mathrm{Pt})$ & $1: 1$ & NA & $\mathrm{NaI}$ & 9 & NA & $\begin{array}{l}74 \\
\left(g^{-1}\right)\end{array}$ & $\begin{array}{l}37 \\
\left(g^{-1}\right)\end{array}$ & 300 & 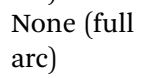 & 49 \\
\hline $\mathrm{C}_{3} \mathrm{~N}_{4}(1 \mathrm{wt} \% \mathrm{Pt})$ & $\mathrm{WO}_{3}$ & $100: 26$ & 200 & rGO & 10 & NA & 2.84 & 1.46 & 300 & $\lambda>420$ & 50 \\
\hline $2 \mathrm{D} \mathrm{C}_{3} \mathrm{~N}_{4}(3 \% \mathrm{Pt})$ & $\alpha-\mathrm{Fe}_{2} \mathrm{O}_{3}\left(0.1 \% \mathrm{RuO}_{2}\right)$ & NA & NA & NA & NA & NA & 38.2 & 38.2 & 300 & $\lambda>400$ & 52 \\
\hline PCN & $\mathrm{Fe}_{2} \mathrm{O}_{3}$ & $1: 10$ & 20 & rGO & Neutral & NA & 43.6 & 21.2 & 300 & $\lambda>400$ & 53 \\
\hline $\mathrm{BDCNN}_{350}(\mathrm{Pt})$ & $\mathrm{BDCNN}_{425}\left(\mathrm{Co}(\mathrm{OH})_{2}\right)$ & $1: 1$ & 20 & NA & Neutral & 1.16 & 24.6 & 12.2 & 300 & $\lambda>420$ & 54 \\
\hline P10 & $\mathrm{BiVO}_{4}$ & $4: 50$ & 4 & $\mathrm{FeCl}_{3}$ & 2.7 & 0.0014 & 5 & 2.7 & 300 & $\lambda>420$ & 55 \\
\hline
\end{tabular}

semiconductor to perform overall water splitting by balancing charges through a redox mediator (Table 1).

Carbon nitride was the first to be reported in $Z$-schemes with $\mathrm{WO}_{3}$ or $\mathrm{BiVO}_{4}$, acting as the oxygen evolution photocatalyst, in the presence of a redox mediator system $\left(\mathrm{I}^{-} / \mathrm{IO}_{3}{ }^{-}\right) .^{49}$ These systems show reproducible $\mathrm{H}_{2}$ and $\mathrm{O}_{2}$ evolution (21.2 and 11.0 $\mu \mathrm{mol} \mathrm{h}{ }^{-1} \mathrm{~g}^{-1}$, respectively) from water under visible light for more than 24 hours (Fig. 3a). The $Z$-scheme concept could also be transferred to linear conjugated polymers, such as the homopolymer of dibenzo[ $[b, d]$ thiophene sulfone (P10, Fig. $3 c){ }^{55}$ An optimised system consisting of $\mathrm{P} 10$ and $\mathrm{BiVO}_{4}$ produced stoichiometric amounts of hydrogen and oxygen with rates of 5 and $2.7 \mu \mathrm{mol} \mathrm{h}^{-1}$ under visible light irradiation and $0.1 \mathrm{bar}$. The system was able to reach equilibrium using either $\mathrm{FeCl}_{3}$ or
$\mathrm{FeCl}_{2}$; however, when using $\mathrm{FeCl}_{3}$ stoichiometric water splitting was only achieved after 10 hours equilibrium. Transient absorption spectroscopy showed that water oxidation with $\mathrm{BiVO}_{4}$ is the kinetic bottleneck of the system. Z-Schemes with mediators have clearly demonstrated that lessons learnt by studying organic materials for hydrogen production translate into overall water splitting systems. However, the fact that mediators have to perform redox reactions at the interface with both photocatalysts reduces the kinetics of the overall systems and sacrificial light absorption by coloured mediators can cause issues.

As a consequence, solid-state electron mediators, such as reduced graphene oxide ( $\mathrm{rGO}$ ) nanosheets, have also since been used in $Z$-scheme type systems with a $\mathrm{PCN} / \mathrm{rGO} / \mathrm{Fe}_{2} \mathrm{O}_{3}$ ternary

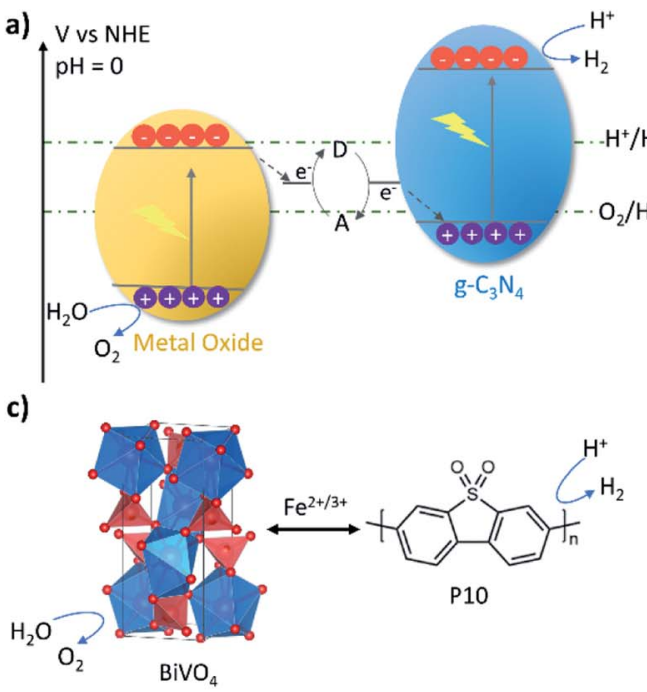

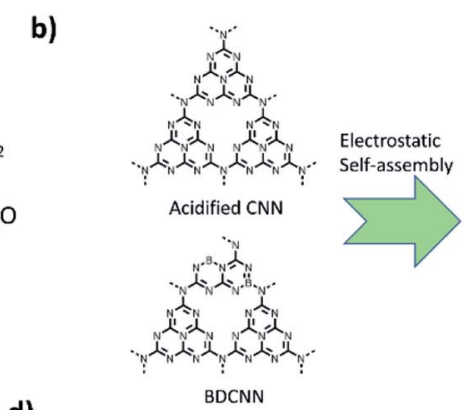

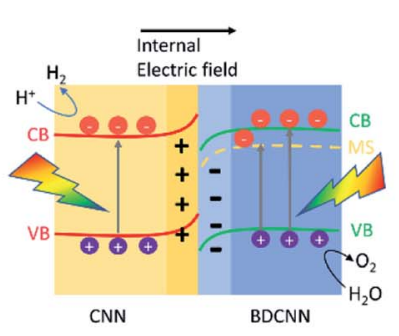

d)
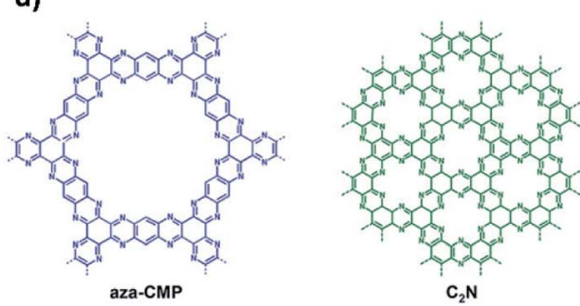

Fig. 3 Overall water splitting Z-scheme systems: (a) carbon nitride $\left(\mathrm{C}_{3} \mathrm{~N}_{4}\right)$ and $\mathrm{BiVO}_{4}$ or $\mathrm{WO}_{3}$ using a redox mediator; ${ }^{49}$ (b) nitrogen-deficient $(\mathrm{CNN})$ and boron-doped (BDCNN) carbon nitride two-dimensional nanosheet heterostructure; ${ }^{54}$ (c) linear conjugated polymer $\mathrm{P} 10$ coupled with $\mathrm{BiVO}_{4}$ using a redox mediator; ${ }^{55}$ (d) a conjugated microporous polymer material coupled with a carbon nitride analogue $\left(\mathrm{C}_{2} \mathrm{~N}\right)$ [figure adapted with permission from ref. 51. Copyright 2018 Wiley-VCH]. 
Table 2 Summary of materials for one step excitation overall water splitting

\begin{tabular}{|c|c|c|c|c|c|c|c|c|c|}
\hline \multirow[b]{2}{*}{ Photocatalyst } & \multirow[b]{2}{*}{ Co-catalyst } & \multirow{2}{*}{$\begin{array}{l}\text { Amount of } \\
\text { photocatalyst } \\
(\mathrm{mg})\end{array}$} & \multirow[b]{2}{*}{$\mathrm{pH}$} & \multirow[b]{2}{*}{$\mathrm{STH} / \%$} & \multicolumn{2}{|c|}{$\begin{array}{l}\text { Gas evolution rates } \\
\left(\mu \mathrm{mol} \mathrm{h}{ }^{-1}\right)\end{array}$} & \multicolumn{2}{|c|}{ Light source } & \multirow[b]{2}{*}{ Ref. } \\
\hline & & & & & $\mathrm{H}_{2}$ & $\mathrm{O}_{2}$ & Power $(\mathrm{W})$ & Filter $(\mathrm{nm})$ & \\
\hline $\mathrm{C}_{3} \mathrm{~N}_{4}$ & Carbon nanodots & 80 & NA & 2.0 & 8.4 & 4.1 & 300 & $\lambda>420$ & 80 \\
\hline PTEB & Pd & 20 & 7 & 0.31 & $102\left(\mathrm{~g}^{-1}\right)$ & & 300 & $\lambda>420$ & 20 \\
\hline РТЕРВ & $\mathrm{Pd}$ & 20 & 7 & 0.6 & $218\left(\mathrm{~g}^{-1}\right)$ & & 300 & $\lambda>420$ & 20 \\
\hline Sea-urchin-structured $\mathrm{C}_{3} \mathrm{~N}_{4}$ & $3 \mathrm{wt} \% \mathrm{Pt}$ & 25 & NA & NA & $41.5\left(\mathrm{~g}^{-1}\right)$ & $20.3\left(\mathrm{~g}^{-1}\right)$ & NA & $\lambda>420$ & 83 \\
\hline CTF-HUST-A1- ${ }^{t} \mathrm{BuOK}$ & $4.5 \mathrm{wt} \% \mathrm{Ni}_{x} \mathrm{P}$ and $3.0 \mathrm{wt} \% \mathrm{Pt}$ & 50 & NA & NA & $25.4\left(\mathrm{~g}^{-1}\right)$ & $12.9\left(\mathrm{~g}^{-1}\right)$ & NA & $\lambda>420$ & 84 \\
\hline $\mathrm{PTI} / \mathrm{Li}^{+} \mathrm{Cl}^{-}$ & $1 \% \mathrm{Pt}$ and $0.5 \%$ Co & 100 & NA & NA & 189 & 91 & 300 & $\lambda>300$ & 85 \\
\hline
\end{tabular}

heterojunction composite achieving efficient overall water splitting with the rates of 43.6 and $21.2 \mu \mathrm{mol} \mathrm{h}^{-1}$ under visible light $(\lambda>400 \mathrm{~nm}) \cdot{ }^{53}$ In these systems, no redox chemistry occurs on the rGO, but it rather acts as an electron conductor. As an example of an all-organic system, carbon nitride doped with nitrogen and boron and loaded with $\mathrm{Co}(\mathrm{OH})_{2}$ was used as the oxygen evolution photocatalyst in conjunction with platinumloaded carbon nitride as the hydrogen evolution catalyst. ${ }^{54}$ The platinum was loaded onto the material via photodeposition of $\mathrm{H}_{2} \mathrm{PtCl}_{6}$ in the presence of methanol before loading with $\mathrm{Co}(\mathrm{OH})_{2}$ by treating a suspension of the composite and $\mathrm{Co}\left(\mathrm{NO}_{3}\right)_{2}$ with ammonia. The authors suggest that electrostatic interactions facilitate the self-assembly of both components and that the interface between the components facilitate charge separation. Overall water splitting rates under visible-light irradiation $(\lambda>420 \mathrm{~nm})$ of $24.55\left(\mathrm{H}_{2}\right)$ and $12.17\left(\mathrm{O}_{2}\right) \mu \mathrm{mol} \mathrm{h}^{-1}$ were reported. A solar-to-hydrogen efficiency of $1.16 \%$ was determined by the authors, which is close to the highest solarto-hydrogen efficiencies reported for inorganic photocatalysts (Fig. 3b). ${ }^{14} \mathrm{~A}$ composite of aza-fused microporous polymers and $\mathrm{C}_{2} \mathrm{~N}$ nanosheets acting as $\mathrm{O}_{2}$ and $\mathrm{H}_{2}$ evolution photocatalysts has also been reported to facilitate overall water splitting with a rate of $22.5 \mu \mathrm{mol} \mathrm{h}{ }^{-1}\left(\mathrm{H}_{2}\right.$, under visible light irradiation) (Fig. 3d). ${ }^{95}$ The report suggests that the system is able to perform overall water splitting without additional co-catalysts.

Systems that do not rely on two separate semiconductors to facilitate overall water splitting have also been reported (Table 2): a nanocomposite of carbon dots and carbon nitride was reported in 2015 with rates of $8.4\left(\mathrm{H}_{2}\right)$ and $4.1\left(\mathrm{O}_{2}\right) \mu \mathrm{mol} \mathrm{h}{ }^{-1}$ under visible light irradiation and an overall solar energy conversion efficiency of $2.0 \%{ }^{80}$ The authors suggest that photocatalytic hydrogen and hydrogen peroxide formation occurs simultaneously via a two electron mechanism, rather than a four electron mechanism that is required when involving water oxidation. The hydrogen peroxide is then decomposed by the carbon dots into hydrogen and oxygen before it can cause damage to the photocatalyst. The mechanism of this composite has also been studied in the following work. ${ }^{96}$ However, more work appears to be necessary to confirm its reproducibility and we note that no independent follow-up studies have been reported to date.

An alternative strategy is to optimize co-catalyst system overall water splitting in pure water without using sacrificial reagents. ${ }^{81}$ Rates of 1.2 and $0.6 \mu \mathrm{mol} \mathrm{h}{ }^{-1}$ were measured experimentally under visible light irradiation and the system was shown to be stable for up to 510 hours. Higher photocatalytic activities were achieved for carbon nitride modified with $\mathrm{CoP}$ and $\mathrm{Pt}$ as co-catalysts (rates were reported to be 2.1 and $1 \mu \mathrm{mol} \mathrm{h}{ }^{-1}$ under visible light). ${ }^{97}$ Single crystalline carbon nitride has been very recently reported with even higher activities for overall water splitting by Xinchen Wang's group. ${ }^{85}$ Polytriazine imide was synthesised with additional lithium chloride and potassium chloride to improve crystallinity and loaded via photodeposition with $\mathrm{Pt} / \mathrm{Co}$ showing an external quantum efficiency of $8 \%$ under a monochromatic light source of $365 \mathrm{~nm}$ for overall water splitting (Fig. 4c). CTFs have also been shown to be able to facilitate overall water splitting when loaded with appropriate co-catalysts and stoichiometric $\mathrm{H}_{2}$ and $\mathrm{O}_{2}$ evolution from water was achieved for a $\mathrm{NiP}_{x}$ and $\mathrm{Pt}$ loaded CTF (Fig. 4b). ${ }^{84}$ The preformed $\mathrm{NiP}_{x}$ was simply mixed with the CFT, which was further loaded with Pt via photodeposition. We expect that this approach is transferable to a range of other organic material classes with appropriate band alignments and expect more reports in this area. In 2017, two 1,3-diyne-linked CMPs (PTEPB and PTEB, Fig. 4d) were reported to facilitate overall water splitting as single component systems without additional co-catalysts. ${ }^{20}$ The reported activity is remarkable with a rate of $218 \mu \mathrm{mol} \mathrm{h}^{-1} \mathrm{~g}^{-1}$ for hydrogen production from water splitting under visible light irradiation. Furthermore, an apparent quantum efficiency as high as $10 \%$ at $420 \mathrm{~nm}$ and a STH of $0.6 \%$ are reported. The authors suggest a molecular mechanism that involves the formation of reactive intermediates via addition and elimination reactions; however, it is only supported by computational studies.

\section{Large-scale applications and challenges}

Given the large amounts of energy that we use, it is clear that scale-up has to be considered when developing materials for water splitting. ${ }^{9}$ The translation into large-scale applications is one of the biggest challenges for overall water splitting systems given that systems are in most cases tested on a small laboratory scale in suspension. Using sheets rather than suspensions avoids the use of agitation that is required in order to prevent 
a)

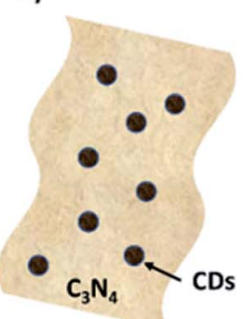

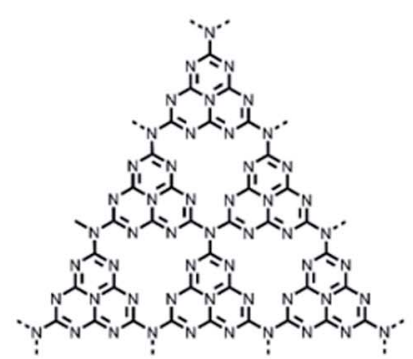

c)

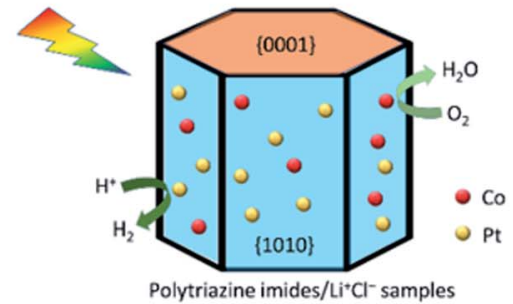

b)

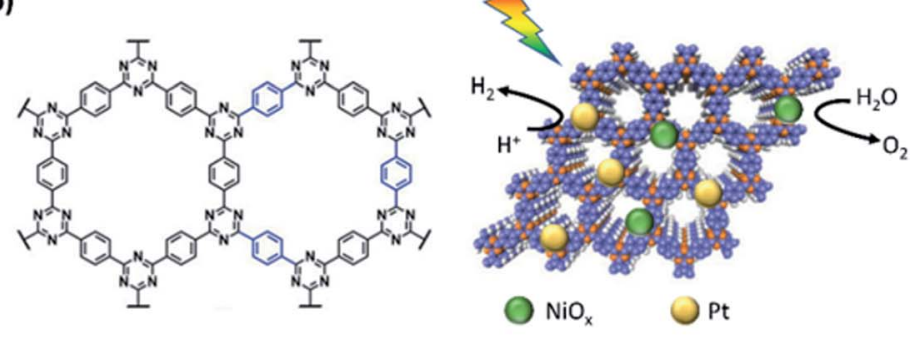

d)

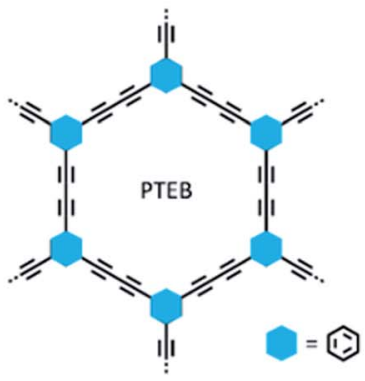<smiles>C#CC1=C=C(C#C)C(=C)C#CC(C#C)C#CC(C#C)C#CC(C#C)C#CC(C#C)C#CC(C#C)C#C1</smiles>

闪

Fig. 4 Single excitation water splitting materials: (a) carbon dots $-\mathrm{C}_{3} \mathrm{~N}_{4} ;{ }^{80}$ (b) crystalline and hydrophilic CTF-HUST-A1 obtained by depositing dual co-catalysts of $\mathrm{NiO}_{x}$ and $\mathrm{Pt}$ [figure adapted with permission from ref. 114. Copyright 2020 Wiley- $\mathrm{VCH}$; (c) structure of $\mathrm{PTI} / \mathrm{Li}^{+} \mathrm{Cl}^{-} \mathrm{Crystal}$ materials; ${ }^{85}$ (d) diyne-linked CMP materials. ${ }^{20}$

the photocatalysts from settling and become inactive as they are no longer exposed to light. However, others ${ }^{98}$ have suggested systems that would use particulate catalysts in a circular system.

Excellent work by Kazunari Domen's group has shown that it is possible to fabricate sheets of multicomponent systems ${ }^{\mathbf{1 4}}$ and large scale panels of single component photocatalysts ${ }^{\mathbf{9 9}}$ that can be produced on a larger scale using screen printing (Fig. 5c). ${ }^{\mathbf{1 0 0}}$

Organic systems have not been studied on a larger scale for overall water splitting. This is perhaps not surprising given that these systems have only been explored over the last ten years. However, systems that study sacrificial half-reactions have been a)
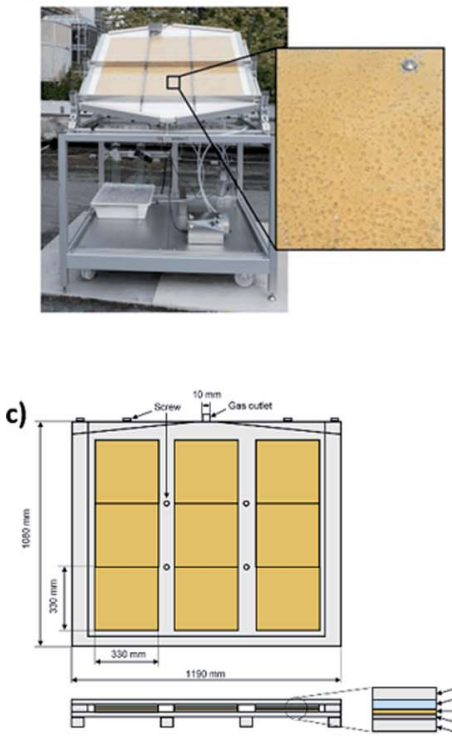
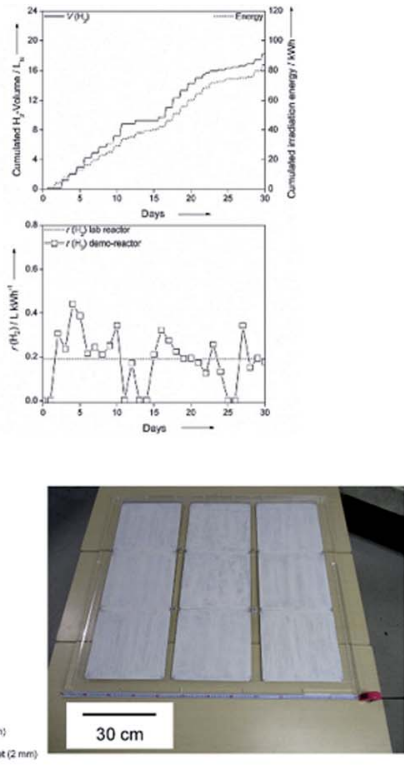

b)
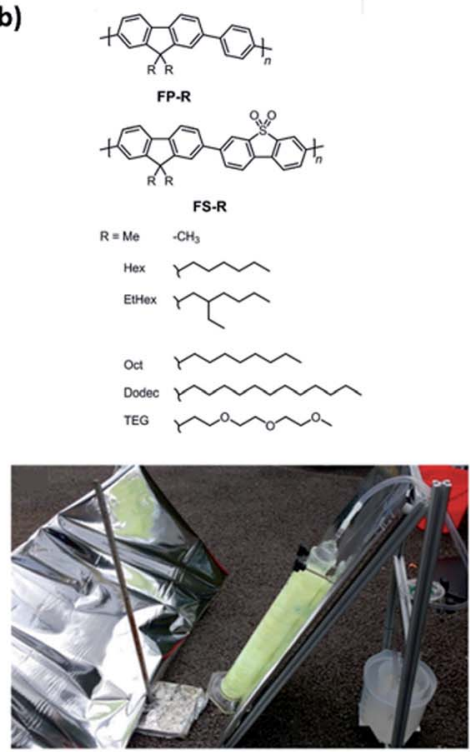

Fig. 5 Large scale water splitting approaches: (a) photograph of a large-scale system for photocatalytic hydrogen production working under natural sunlight using an immobilized Ptampg-CN catalyst [figure adapted with permission from ref. 101. Copyright 2015 Wiley-VCH]; (b) structures of soluble polymers and the side view of the photoreactor set-up with a reflective panel and polymer-coated glass fibers submerged in 5 vol\% TEA and connected to a hydrogen collection vessel (right) [adapted from ref. 104 with permission from the Royal Society of Chemistry]; (c) overall water splitting panels containing $\mathrm{SrTiO}_{3}: \mathrm{Al}_{\text {s sheets }}^{99}$ [reprinted from Joule, vol. 2, Y. Goto et al., A Particulate Photocatalyst Water-Splitting Panel for Large-Scale Solar Hydrogen Generation, 509-520, Copyright (2018), with permission from Elsevier]. 
reported, such as a demonstrator device that uses immobilised carbon nitride loaded with platinum and facilitates hydrogen production in the presence of a hole scavenger (Fig. 5a). ${ }^{\mathbf{1 0 1}}$ Particularly exciting is the prospect of polymer photocatalysts that are soluble in organic solvents as this offers excellent opportunities for solution processing, such as large-scale printing on flexible substrates using established techniques such as roll-to-roll printing. ${ }^{\mathbf{1 0 2}}$ Solution-processible polymer photocatalysts have shown that they retain activity for sacrificial hydrogen production when cast onto flat supports ${ }^{\mathbf{1 0 3}}$ and onto fibres, ${ }^{\mathbf{1 0 4}}$ allowing for hydrogen production on a larger scale (Fig. 5b).

To obtain such systems, further work is required to develop solution processable systems that facilitate overall water splitting with appropriate co-catalysts or two component systems consisting of hydrogen and oxygen production polymers.

\section{Conclusions and outlook}

Overall, it is very clear that polymeric materials have significant potential as overall water splitting photocatalysts as outlined in this highlight. The fact that these materials are easily tunable by structural modification and that they are made from earth abundant elements makes them ideal candidates for large scale applications.

It is also clear that more research needs to be conducted to explore overall water splitting rather than sacrificial hydrogen production from water alone. Having said this, there is still value in exploring new concepts under sacrificial conditions to transition these towards overall water splitting later on as has been demonstrated for a few organic systems already.

The water oxidation reaction still remains a significant challenge for organic photocatalysts and only a few examples have been reported so far. This area needs much more attention than it currently has to generate new ideas and materials. The small number of materials reported in most studies, together with the fact that silver nitride results in the passivation of the photocatalyst surface by depositing elementary silver, makes it very difficult to establish structure-property relationships and to make statements about the potential stability of the systems. New materials are needed whose optical absorption matches the solar spectrum better, while maintaining suitable HOMO levels for water oxidation, to bring the performance of the material closer to the required STH of $10 \% .^{9}$

Based on the literature, it appears that there is no clear consensus in the community whether co-catalysts are required. It seems that the metal co-catalyst plays a very important role; however, hydrogen and oxygen production, as well as overall water splitting via metal-free routes, has been reported. It is clear that a lot more work has to be done in this area to understand these systems and either focus on systems that facilitate water splitting without metal co-catalysts (if this is found to be indeed reproducible) or understand the exact role of precious co-catalysts and explore alternative non-precious cocatalysts for scale-up in the future (if co-catalysts are found to be essential).
Generally speaking, much more understanding of organic polymer overall water splitting systems is needed to guide the approaches used by synthetic chemists. For this, a range of spectroscopic and other methods are available that have been used already fairly extensively on sacrificial systems. ${ }^{\mathbf{1 0 5}}$

Exciton separation also seems to be limiting in overall water splitting systems lowering the overall performance as suggested by many reports. To overcome this issue, new concepts are needed, such as the combination of multiple components to combine photocatalysts to drive both half reactions and facilitate efficient electron transfer. For example, using stacks of molecular crystals or COFs or confining a secondary phase such as a soluble conjugated polymer in the pore structure of a CMP are possible approaches.

Balancing of the surface reaction rates between either two components or a single component system for hydrogen and oxygen production is also important to achieve high STHs and also to ensure stable stoichiometric water splitting avoiding access to charge carriers that could lead to side-reactions and be damaging to the system. Given the sluggish kinetics of water oxidation, this again appears to be a significant challenge for organic materials and systematic studies into co-catalysts for water oxidation are needed; for example plasmonic systems have not been explored to date. ${ }^{\mathbf{1 0 6}}$

A recent demonstration of efforts employed for the screening of photocatalyst activity illustrates data-driven approaches that ${ }^{\mathbf{1 8 , 1 0 7}}$ could play an important role in streamlining the search for new materials. These are further augmented by machinelearning driven automated laboratories that can not only synthesize, but also rapidly determine HERs and OERs as well as mechanisms therein, but require innovation in rapid experimental testing procedures, multi-objective optimisation, including in situ measurements and embedded physics and chemistry knowledge. Such efforts are expected to significantly accelerate the search for new organic photocatalysts.

Furthermore, predictive approaches have been underutilised and only a few studies have been reported that make suggestions for potential systems that could be used for overall water splitting. ${ }^{108,109}$ One potential issue is that the exact mechanism is not well understood making it hard to suggest synthetic targets. Another issue is the fact that often other factors that are inherently difficult or impossible to predict, such as wettability or particle size, are found to be significant contributors to the overall photocatalytic performance. ${ }^{18,33}$

Going forward, solution-processable materials offer huge potential for large-scale applications as cheap and scalable printing methods can be used; however, no examples have been reported so far. Organic materials might also offer potential advantages, such as an increased surface area by swelling in contact with water thus allowing access to a larger number of active sites compared to inorganic semiconductors. ${ }^{104}$ Supports and designs for large scale panel systems also require further research. For example, transparent substrates with polymer films could be used to harvest more sunlight as deeper layers will be able to use photons that have passed through the top layer, a concept that has been demonstrated for stacks of polymer photocatalysts on glass substrates. ${ }^{\mathbf{1 0 4}}$ 
As far as we can see there have been few follow-up studies on the reported organic systems for overall water splitting. To enable this in the future, clear and detailed experimental procedures that allow for the reproduction of materials are needed. This goes in hand-in-hand with the standardisation of measurements that will be of importance to guide the field towards more efficient overall water splitting systems. ${ }^{\mathbf{1 1 0 , 1 1 1}}$ Solar-to-hydrogen efficiencies using solar simulator light sources have to be reported with the measurement conditions that were used (e.g. pressure, catalyst concentration, and set-up type). Ultimately, standardised efficiency accreditation ${ }^{\mathbf{1 1 2}}$ similar to the existing accreditation of solar cells ${ }^{\mathbf{1 1 3}}$ is needed for reliable and reproducible results for overall water splitting systems. Finally, beyond lab-scale studies much more work is needed to explore scale-up and testing under real-world conditions in terms of light intensity, pressure and longer-term stability. Only then we will be able to ascertain the true potential of polymer photocatalysts for overall water splitting.

\section{Conflicts of interest}

There are no conflicts to declare.

\section{Acknowledgements}

R. S. S thanks the University of Strathclyde for financial support through The Strathclyde Chancellor's Fellowship Scheme. Y. B. and $\mathrm{K}$. $\mathrm{H}$ thank the Accelerated Materials Development for Manufacturing Program at A*STAR via the AME Programmatic Fund by the Agency for Science, Technology and Research under grant no. A1898b0043.

\section{References}

1 M. I. Hoffert, Science, 2010, 329, 1292-1294.

2 D. Shindell and C. J. Smith, Nature, 2019, 573, 408-411.

3 H. Stančin, H. Mikulčić, X. Wang and N. Duić, Renewable Sustainable Energy Rev., 2020, 128, 109927.

4 S. Koohi-Fayegh and M. A. Rosen, J. Energy Storage, 2020, 27, 101047.

5 B. You and Y. Sun, Acc. Chem. Res., 2018, 51, 1571-1580.

6 M. Gr, Nature, 2001, 414, 338-344.

7 Z. Wang, C. Li and K. Domen, Chem. Soc. Rev., 2019, 48, 2109-2125.

8 Q. Wang and K. Domen, Chem. Rev., 2020, 120, 919-985.

9 K. Maeda, J. Photochem. Photobiol. C Photochem. Rev., 2011, 12, 237-268.

10 A. Kudo and Y. Miseki, Chem. Soc. Rev., 2009, 38, 253-278. 11 D. J. Martin, P. J. T. Reardon, S. J. A. Moniz and J. Tang, J. Am. Chem. Soc., 2014, 136, 12568-12571.

12 B. J. Ng, L. K. Putri, L. L. Tan, P. Pasbakhsh and S. P. Chai, Chem. Eng. J., 2017, 316, 41-49.

13 A. Iwase, Y. H. Ng, Y. Ishiguro, A. Kudo and R. Amal, J. Am. Chem. Soc., 2011, 133, 11054-11057.

14 Q. Wang, T. Hisatomi, Q. Jia, H. Tokudome, M. Zhong, C. Wang, Z. Pan, T. Takata, M. Nakabayashi, N. Shibata,
Y. Li, I. D. Sharp, A. Kudo, T. Yamada and K. Domen, Nat. Mater., 2016, 15, 611-615.

15 T. Takata, J. Jiang, Y. Sakata, M. Nakabayashi, N. Shibata, V. Nandal, K. Seki, T. Hisatomi and K. Domen, Nature, 2020, 581, 411-414.

16 H. Lyu, T. Hisatomi, Y. Goto, M. Yoshida, T. Higashi, M. Katayama, T. Takata, T. Minegishi, H. Nishiyama, T. Yamada, Y. Sakata, K. Asakura and K. Domen, Chem. Sci., 2019, 10, 3196-3201.

17 R. S. Sprick, B. Bonillo, R. Clowes, P. Guiglion, N. J. Brownbill, B. J. Slater, F. Blanc, M. A. Zwijnenburg, D. J. Adams and A. I. Cooper, Angew. Chem., Int. Ed., 2016, 55, 1792-1796.

18 Y. Bai, L. Wilbraham, B. Slater, M. Zwijnenburg, R. Sprick and A. Cooper, J. Am. Chem. Soc., 2019, 141, 9063-9071.

19 R. S. Sprick, C. M. Aitchison, E. Berardo, L. Turcani, L. Wilbraham, B. M. Alston, K. E. Jelfs, M. A. Zwijnenburg and A. I. Cooper, J. Mater. Chem. A, 2018, 6, 11994-12003.

20 L. Wang, Y. Wan, Y. Ding, S. Wu, Y. Zhang, X. Zhang, G. Zhang, Y. Xiong, X. Wu, J. Yang and H. Xu, Adv. Mater., 2017, 29, 1702428.

21 S. Matsuoka, T. Kohzuki, Y. Kuwana, A. Nakamura and S. Yanagida, J. Chem. Soc., Perkin Trans. 2, 1992, 679.

22 X. Wang, L. Chen, S. Y. Chong, M. A. Little, Y. Wu, W.-H. Zhu, R. Clowes, Y. Yan, M. A. Zwijnenburg, R. S. Sprick and A. I. Cooper, Nat. Chem., 2018, 10, 11801189.

23 S. Bi, Z. Lan, S. Paasch, W. Zhang, Y. He, C. Zhang, F. Liu, D. Wu, X. Zhuang, E. Brunner, X. Wang and F. Zhang, Adv. Funct. Mater., 2017, 27, 1703146.

24 C. B. Meier, R. S. Sprick, A. Monti, P. Guiglion, J.-S. M. Lee, M. A. Zwijnenburg and A. I. Cooper, Polymer, 2017, 126, 283-290.

25 R. S. Sprick, A. Thomas and U. Scherf, Polym. Chem., 2010, 1, 283.

26 X. Wang, K. Maeda, A. Thomas, K. Takanabe, G. Xin, J. M. Carlsson, K. Domen and M. Antonietti, Nat. Mater., 2009, 8, 76-80.

27 Y. Wang, X. Wang and M. Antonietti, Angew. Chem., Int. Ed., 2012, 51, 68-89.

28 J. Wen, J. Xie, X. Chen and X. Li, Appl. Surf. Sci., 2017, 391, 72-123.

29 L. Lin, Z. Yu and X. Wang, Angew. Chem., Int. Ed., 2019, 58, 6164-6175.

30 S. Cao, J. Low, J. Yu and M. Jaroniec, Adv. Mater., 2015, 27, 2150-2176.

31 G. Zhang, L. Lin, G. Li, Y. Zhang, A. Savateev, S. Zafeiratos, X. Wang and M. Antonietti, Angew. Chem., Int. Ed., 2018, 57, 9372-9376.

32 Z. Qian, Z. J. Wang and K. A. I. Zhang, Chem. Mater., 2021, 33, 1909-1926.

33 C. B. Meier, R. Clowes, E. Berardo, K. E. Jelfs, M. A. Zwijnenburg, R. S. Sprick and A. I. Cooper, Chem. Mater., 2019, 31, 8830-8838.

34 J.-X. Jiang, F. Su, A. Trewin, C. D. Wood, N. L. Campbell, H. Niu, C. Dickinson, A. Y. Ganin, M. J. Rosseinsky, 
Y. Z. Khimyak and A. I. Cooper, Angew. Chem., Int. Ed., 2007, 46, 8574-8578.

35 R. S. Sprick, J. X. Jiang, B. Bonillo, S. Ren, T. Ratvijitvech, P. Guiglion, M. A. Zwijnenburg, D. J. Adams and A. I. Cooper, J. Am. Chem. Soc., 2015, 137, 3265-3270.

36 Y. Xu, N. Mao, C. Zhang, X. Wang, J. Zeng, Y. Chen, F. Wang and J. X. Jiang, Appl. Catal., B, 2018, 228, 1-9.

37 Y. Liu, Z. Liao, X. Ma and Z. Xiang, ACS Appl. Mater. Interfaces, 2018, 10, 30698-30705.

38 Z. A. Lan, W. Ren, X. Chen, Y. Zhang and X. Wang, Appl. Catal., B, 2019, 245, 596-603.

39 C. Yang, B. C. Ma, L. Zhang, S. Lin, S. Ghasimi, K. Landfester, K. A. I. Zhang and X. Wang, Angew. Chem., Int. Ed., 2016, 55, 9202-9206.

40 L. Stegbauer, K. Schwinghammer and B. V. Lotsch, Chem. Sci., 2014, 5, 2789-2793.

41 V. S. Vyas, F. Haase, L. Stegbauer, G. Savasci, F. Podjaski, C. Ochsenfeld and B. V Lotsch, Nat. Commun., 2015, 6, 8508.

42 S. Ghosh, A. Nakada, M. A. Springer, T. Kawaguchi, K. Suzuki, H. Kaji, I. Baburin, A. Kuc, T. Heine, H. Suzuki, R. Abe and S. Seki, J. Am. Chem. Soc., 2020, 142, 9752-9762.

43 S. Yanagida, A. Kabumoto, K. Mizumoto, C. Pac and K. Yoshino, J. Chem. Soc., Chem. Commun., 1985, 474-475.

44 J. Kosco, M. Bidwell, H. Cha, T. Martin, C. T. Howells, M. Sachs, D. H. Anjum, S. Gonzalez Lopez, L. Zou, A. Wadsworth, W. Zhang, L. Zhang, J. Tellam, R. Sougrat, F. Laquai, D. M. Delongchamp, J. R. Durrant and I. McCulloch, Nat. Mater., 2020, 19, 559-565.

45 H. Yang, X. Li, R. S. Sprick and A. I. Cooper, Chem. Commun., 2020, 56, 6790-6793.

46 X. Zhang, F. Shen, Z. Hu, Y. Wu, H. Tang, J. Jia, X. Wang, F. Huang and Y. Cao, ACS Sustainable Chem. Eng., 2019, 7, 4128-4135.

47 A. Liu, L. Gedda, M. Axelsson, M. Pavliuk, K. Edwards, L. Hammarström and H. Tian, J. Am. Chem. Soc., 2021, 143, 2875-2885.

48 C. M. Aitchison, C. M. Kane, D. P. McMahon, P. R. Spackman, A. Pulido, X. Wang, L. Wilbraham, L. Chen, R. Clowes, M. A. Zwijnenburg, R. S. Sprick, M. A. Little, G. M. Day and A. I. Cooper, J. Mater. Chem. A, 2020, 8, 7158-7170.

49 D. J. Martin, P. J. T. Reardon, S. J. A. Moniz, J. Tang, P. James, T. Reardon, S. J. A. Moniz and J. Tang, J. Am. Chem. Soc., 2014, 136, 1-6.

50 G. Zhao, X. Huang, F. Fina, G. Zhang and J. T. S. Irvine, Catal. Sci. Technol., 2015, 5, 3416-3422.

51 L. Wang, X. Zheng, L. Chen, Y. Xiong and H. Xu, Angew. Chem., Int. Ed., 2018, 57, 3454-3458.

52 X. She, J. Wu, H. Xu, J. Zhong, Y. Wang, Y. Song, K. Nie, Y. Liu, Y. Yang, M. T. F. Rodrigues, R. Vajtai, J. Lou, D. Du, H. Li and P. M. Ajayan, Adv. Energy Mater., 2017, 7, $1-7$.

53 Z. Pan, G. Zhang and X. Wang, Angew. Chem., Int. Ed., 2019, 58, 7102-7106.

54 D. Zhao, Y. Wang, C. Dong, Y. Huang, J. Chen, F. Xue, S. Shen and L. Guo, Nat. Energy, 2021, 6, 388-397.
55 Y. Bai, K. Nakagawa, A. Cowan, C. M. Aitchison, Y. Yamaguchi, M. Zwijnenburg, A. Kudo, R. S. Sprick and A. Cooper, J. Mater. Chem. A, 2020, 6, 4883-5230.

56 M. Sachs, H. Cha, J. Kosco, C. M. Aitchison, L. Francàs, S. Corby, C.-L. Chiang, A. A. Wilson, R. Godin, A. FaheyWilliams, A. I. Cooper, R. S. Sprick, I. McCulloch and J. R. Durrant, J. Am. Chem. Soc., 2020, 142, 14574-14587.

57 J. Kosco, M. Sachs, R. Godin, M. Kirkus, L. Francas, M. Bidwell, M. Qureshi, D. Anjum, J. R. Durrant and I. McCulloch, Adv. Energy Mater., 2018, 8, 1802181.

58 L. Li, Z. Cai, Q. Wu, W. Y. Lo, N. Zhang, L. X. Chen and L. Yu, J. Am. Chem. Soc., 2016, 138, 7681-7686.

59 Y. Bai, L. Wilbraham, B. J. Slater, M. A. Zwijnenburg, R. S. Sprick and A. I. Cooper, J. Am. Chem. Soc., 2019, 141, 9063-9071.

60 L. Zhang, Y. Zhang, X. Huang, L. Tao and Y. Bi, Appl. Catal., B, 2021, 283, 119633.

61 Z. Cheng, K. Zheng, G. Lin, S. Fang, L. Li, J. Bi, J. Shen and L. Wu, Nanoscale Adv., 2019, 1, 2674-2680.

62 X. Cao, Y. Li, B. Liu, A. Gao, J. Cao, Y. Yu and X. Hei, New J. Chem., 2019, 43, 7093-7098.

63 P. B. Pati, G. Damas, L. Tian, D. L. A. Fernandes, L. Zhang, I. B. Pehlivan, T. Edvinsson, C. M. Araujo and H. Tian, Energy Environ. Sci., 2017, 10, 1372-1376.

64 P. Guiglion, C. Butchosa and M. A. Zwijnenburg, J. Mater. Chem. A, 2014, 2, 11996-12004.

65 R. S. Sprick, Z. Chen, A. J. Cowan, Y. Bai, C. M. Aitchison, Y. Fang, M. A. Zwijnenburg, A. I. Cooper and X. Wang, Angew. Chem., Int. Ed., 2020, 132, 18854-18859.

66 G. Zhang, C. Huang and X. Wang, Small, 2015, 11, 12151221.

67 D. Kong, Y. Zheng, M. Kobielusz, Y. Wang, Z. Bai, W. Macyk, X. Wang and J. Tang, Mater. Today, 2018, 21, 897-924.

68 H. Zhang, W. Tian, X. Guo, L. Zhou, H. Sun, M. O. Tadé and S. Wang, ACS Appl. Mater. Interfaces, 2016, 8, 35203-35212. 69 L. Wang, Y. Wan, Y. Ding, Y. Niu, Y. Xiong, X. Wu and H. Xu, Nanoscale, 2017, 9, 4090-4096.

70 J. Zhang, J. Sun, K. Maeda, K. Domen, P. Liu, M. Antonietti, X. Fu and X. Wang, Energy Environ. Sci., 2011, 4, 675.

71 A. Mishra, A. Mehta, S. Basu, N. P. Shetti, K. R. Reddy and T. M. Aminabhavi, Carbon, 2019, 149, 693-721.

72 Y. Kan, Y. Zhu, Z. Liu, L. Zhang, J. Chen and Y. Cao, Macromol. Rapid Commun., 2015, 36, 1393-1401.

73 R. S. Sprick, L. Wilbraham, Y. Bai, P. Guiglion, A. Monti, R. Clowes, A. I. Cooper and M. A. Zwijnenburg, Chem. Mater., 2018, 30, 5733-5742.

74 J. Bi, W. Fang, L. Li, J. Wang, S. Liang, Y. He, M. Liu and L. Wu, Macromol. Rapid Commun., 2015, 36, 1799-1805.

75 J. Xie, S. A. Shevlin, Q. Ruan, S. J. A. Moniz, Y. Liu, X. Liu, Y. Li, C. C. Lau, Z. X. Guo and J. Tang, Energy Environ. Sci., 2018, 11, 1617-1624.

76 Z. Zhang, X. Chen, H. Zhang, W. Liu, W. Zhu and Y. Zhu, Adv. Mater., 2020, 32, 1-6.

77 J. Patel, X. Yuan, S. M. Marinho, W. Leibl, H. Remita and A. Aukauloo, Chem. Sci., 2020, 11, 7324-7328.

78 J. Chen, X. Tao, C. Li, Y. Ma, L. Tao, D. Zheng, J. Zhu, H. Li, R. Li and Q. Yang, Appl. Catal., B, 2020, 262, 118271. 
79 X. Ma, H. Wang, J. Cheng, H. Cheng, L. Wang, X. Wu and H. Xu, Chin. J. Chem., 2021, 39, 1079-1084.

80 J. Liu, Y. Liu, N. Liu, Y. Han, X. Zhang, H. Huang, Y. Lifshitz, S.-T. S.-T. Lee, J. Zhong and Z. Kang, Science, 2015, 347, 970-974.

81 G. Zhang, Z.-A. Lan, L. Lin, S. Lin and X. Wang, Chem. Sci., 2016, 7, 3062-3066.

82 Z. Mo, J. Di, P. Yan, C. Lv, X. Zhu, D. Liu, Y. Song, C. Liu, Q. Yu, H. Li, Y. Lei, H. Xu and Q. Yan, Small, 2020, 16, 1-10.

83 Y. Zeng, H. Li, J. Luo, J. Yuan, L. Wang, C. Liu, Y. Xia, M. Liu, S. Luo, T. Cai, S. Liu and J. C. Crittenden, Appl. Catal., B, 2019, 249, 275-281.

84 S. Zhang, G. Cheng, L. Guo, N. Wang, B. Tan and S. Jin, Angew. Chem., Int. Ed., 2020, 59, 6007-6014.

85 L. Lin, Z. Lin, J. Zhang, X. Cai, W. Lin, Z. Yu and X. Wang, Nat. Catal., 2020, 3, 649-655.

86 S. Scholz, D. Kondakov, B. Lüssem and K. Leo, Chem. Rev., 2015, 115, 8449-8503.

87 L. Romaner, A. Pogantsch, P. Scandiucci de Freitas, U. Scherf, M. Gaal, E. Zojer and E. J. W. List, Adv. Funct. Mater., 2003, 13, 597-601.

88 S. Alem, S. Wakim, J. Lu, G. Robertson, J. Ding and Y. Tao, ACS Appl. Mater. Interfaces, 2012, 4, 2993-2998.

89 B. Louis, S. Caubergh, P.-O. Larsson, Y. Tian and I. G. Scheblykin, Phys. Chem. Chem. Phys., 2018, 20, 18291837.

90 M. Salvador, N. Gasparini, J. D. Perea, S. H. Paleti, A. Distler, L. N. Inasaridze, P. Troshin, L. Lüer, H.-J. Egelhaaf and C. J. Brabec, Energy Environ. Sci., 2017, 2005-2016.

91 C. M. Aitchison, M. Sachs, M. A. Little, L. Wilbraham, N. J. Brownbill, C. M. Kane, F. Blanc, M. A. Zwijnenburg, J. R. Durrant, R. S. Sprick and A. I. Cooper, Chem. Sci., 2020, 11, 8744-8756.

92 T. Tromholt, M. V. Madsen, J. E. Carlé, M. Helgesen and F. C. Krebs, J. Mater. Chem., 2012, 22, 7592.

93 H. W. Sarkas, W. Kwan, S. R. Flom, C. D. Merritt and Z. H. Kafafi, J. Phys. Chem., 1996, 100, 5169-5171.

94 H. Neugebauer, C. Brabec, J. C. Hummelen and N. S. Sariciftci, Sol. Energy Mater. Sol. Cells, 2000, 61, 35-42. 95 L. Wang, X. Zheng, L. Chen, Y. Xiong and H. Xu, Angew. Chem., 2018, 57, 3454-3458.

96 D. Qu, J. Liu, X. Miao, M. Han, H. Zhang, Z. Cui, S. Sun, Z. Kang, H. Fan and Z. Sun, Appl. Catal., B, 2018, 227, 418-424.

97 Z. Pan, Y. Zheng, F. Guo, P. Niu and X. Wang, ChemSusChem, 2017, 10, 87-90.
98 Y. Zhao, C. Ding, J. Zhu, W. Qin, X. Tao, F. Fan, R. Li and C. Li, Angew. Chem., Int. Ed., 2020, 59, 9653-9658.

99 Y. Goto, T. Hisatomi, Q. Wang, T. Higashi, K. Ishikiriyama, T. Maeda, Y. Sakata, S. Okunaka, H. Tokudome, M. Katayama, S. Akiyama, H. Nishiyama, Y. Inoue, T. Takewaki, T. Setoyama, T. Minegishi, T. Takata, T. Yamada and K. Domen, Joule, 2018, 2, 509-520.

100 Q. Wang, S. Okunaka, H. Tokudome, T. Hisatomi, M. Nakabayashi, N. Shibata, T. Yamada and K. Domen, Joule, 2018, 2, 2667-2680.

101 M. Schröder, K. Kailasam, J. Borgmeyer, M. Neumann, A. Thomas, R. Schomäcker and M. Schwarze, Energy Technol., 2015, 3, 1014-1017.

102 R. Søndergaard, M. Hösel, D. Angmo, T. T. Larsen-Olsen and F. C. Krebs, Mater. Today, 2012, 15, 36-49.

103 D. J. Woods, R. S. Sprick, C. L. Smith, A. J. Cowan and A. I. Cooper, Adv. Energy Mater., 2017, 7, 1700479.

104 D. J. Woods, S. A. J. Hillman, D. Pearce, L. Wilbraham, L. Q. Flagg, W. Duffy, I. McCulloch, J. R. Durrant, A. A. Y. Guilbert, M. A. Zwijnenburg, R. S. Sprick, J. Nelson and A. I. Cooper, Energy Environ. Sci., 2020, 13, 1843-1855.

105 E. Mitchell, A. Law and R. Godin, Chem. Commun., 2021, 57, 1550-1567.

106 S. Wang, Y. Gao, S. Miao, T. Liu, L. Mu, R. Li, F. Fan and C. Li, J. Am. Chem. Soc., 2017, 139, 11771-11778.

107 B. Burger, P. M. Maffettone, V. V. Gusev, C. M. Aitchison, Y. Bai, X. Wang, X. Li, B. M. Alston, B. Li, R. Clowes, N. Rankin, B. Harris, R. S. Sprick and A. I. Cooper, Nature, 2020, 583, 237-241.

108 Y. Wan, L. Wang, H. Xu, X. Wu and J. Yang, J. Am. Chem. Soc., 2020, 142, 4508-4516.

$109 \mathrm{H}$. Yu and D. Wang, ChemRxiv, 2021, DOI: 10.26434/ chemrxiv.14159444.v2.

110 Y. Wang, A. Vogel, M. Sachs, R. S. Sprick, L. Wilbraham, S. J. A. Moniz, R. Godin, M. A. Zwijnenburg, J. R. Durrant, A. I. Cooper and J. Tang, Nat. Energy, 2019, 4, 746-760.

111 H. A. Vignolo-González, S. Laha, A. Jiménez-Solano, T. Oshima, V. Duppel, P. Schützendübe and B. V. Lotsch, Matter, 2020, 3, 464-486.

112 Z. Wang, T. Hisatomi, R. Li, K. Sayama, G. Liu, K. Domen, C. Li and L. Wang, Joule, 2021, 5, 344-359.

113 M. Green, E. Dunlop, J. Hohl-Ebinger, M. Yoshita, N. Kopidakis and X. Hao, Prog. Photovoltaics Res. Appl., 2021, 29, 3-15.

114 S. Zhang, G. Cheng, L. Guo, N. Wang, B. Tan and S. Jin, Angew. Chem., Int. Ed., 2020, 59, 6007-6014. 